\title{
Available in Selected Metros Only \\ Rural Melancholy and the Promise of Online Connectivity
}

Melissa GREgG

This essay attempts to suggest some features comprising an ontology of the nonmetro. It is an experiment in applying what might be considered a highly abstract and academic interest-affect theory-to a specific policy debate: the logistics of broadband provision in rural Australia. My intention, following the work of Kathleen Stewart, is not so much to bring these two objects together to provide a story of 'what's going on'. Rather, it is to 'fashion some form of address that is adequate' to the ordinary affects of rural life, in order to move beyond a certain impasse in the imaginative lexicon of telecommunications policy, advertising and activism. ${ }^{1}$ A further aim is to reveal some of the limitations in the complex ideology of fulfilment contained in the twin promises of online connectivity and citizenship that are unevenly distributed in knowledge economies.

In terms of cultural studies' past and future preoccupations, this project recognises the benefits to be gained from speaking across established disciplinary investments when matters of equity are at stake. In drawing attention to the worlds 'whose forms of living are now being composed and suffered', affect theory is one way to trouble the certainty with which rural stakeholders are identified and political priorities mobilised on matters of national significance. ${ }^{2}$ The particular context for this discussion is the Australian Government's commitment to build a national broadband network to meet the needs of a wider segment of the population 
than market provision currently services. Initially, this election pledge was to bring high-speed internet to 98 per cent of the population by 2010, but at the time of writing, this objective has been modified to only 90 per cent of the nation's residents, although at much higher speeds than originally suggested. The government's amended proposal intends to develop a business model for more equitable broadband access that will be turned over to the market once its viability is proven. It follows an announcement made by the nation's largest telecommunications provider, Telstra, to equip homes in inner-city Melbourne with broadband speeds significantly faster than the national average.

The vicissitudes of market-led technology adoption are an obvious point of departure for a cultural studies critique. However, in what follows I seek to update cultural studies' concern with city-country divides which stretches back as far as the defining account provided by Raymond Williams. ${ }^{3}$ As I have argued previously, Williams was one of the first cultural studies scholars to introduce an affective register to cultural studies writing and politics. ${ }^{4}$ This essay follows his example by approximating what it feels like to be distant from the visions of online connectivity currently celebrated by government and telco promoters alike. In doing so, it focuses on 'scenes of ordinary survival, not transgression, on disappointment, not refusal, to derive the register of critique'. ${ }^{5}$

- HAPPY HOMES

To give a sense of the optimistic visions of broadband connection that have appeared regularly in recent media, I begin with two images. The first is an unremarkable Australian brick and tile home, its interior exposed akin to a child's dolls' house. Inside, each room is occupied by a member of a 'typical' family. 6 The father is in the lounge room, feet up on the coffee table, watching a screen from the couch. The mother is in the kitchen, also attending a computer. Upstairs, four rooms are occupied by individual children, also involved in networked screen activity. Apart from two young girls together in a bedroom, each family member is alone.

Australian readers may recognise this as a description of Telstra Bigpond's large scale advertising campaign for broadband services that has appeared in magazines, newspaper inserts, mailboxes, television commercials and online. Among the things to note about it are the individuating tendencies it naturalises: computers 
generate a succession of isolated consumer experiences and market segments, which together combine to form a contained, individual household. The nuclear family and the home are synonymous and comprise an idyllic image of community captured in the Bigpond slogan: 'We all get on when we all get on.' The advertisement is a tiny rendition of the elements comprising suburban happiness. Whether parody or imitation, it is vision of domestic harmony that gains coherence through the relationships being formed outside the family unit. ${ }^{7}$

The second image is a blue Volkswagon Kombi van made of cardboard (Figure 1). It is a DIY construction put together from a letterbox mailout delivered some time in 2008. The Kombi comes from another Telstra campaign, this time for wireless broadband. Not only does it appear in the significant number of media outlets already mentioned, it also occupies prominent advertising space in public locations-for instance, Sydney Domestic Airport (Figure 2).

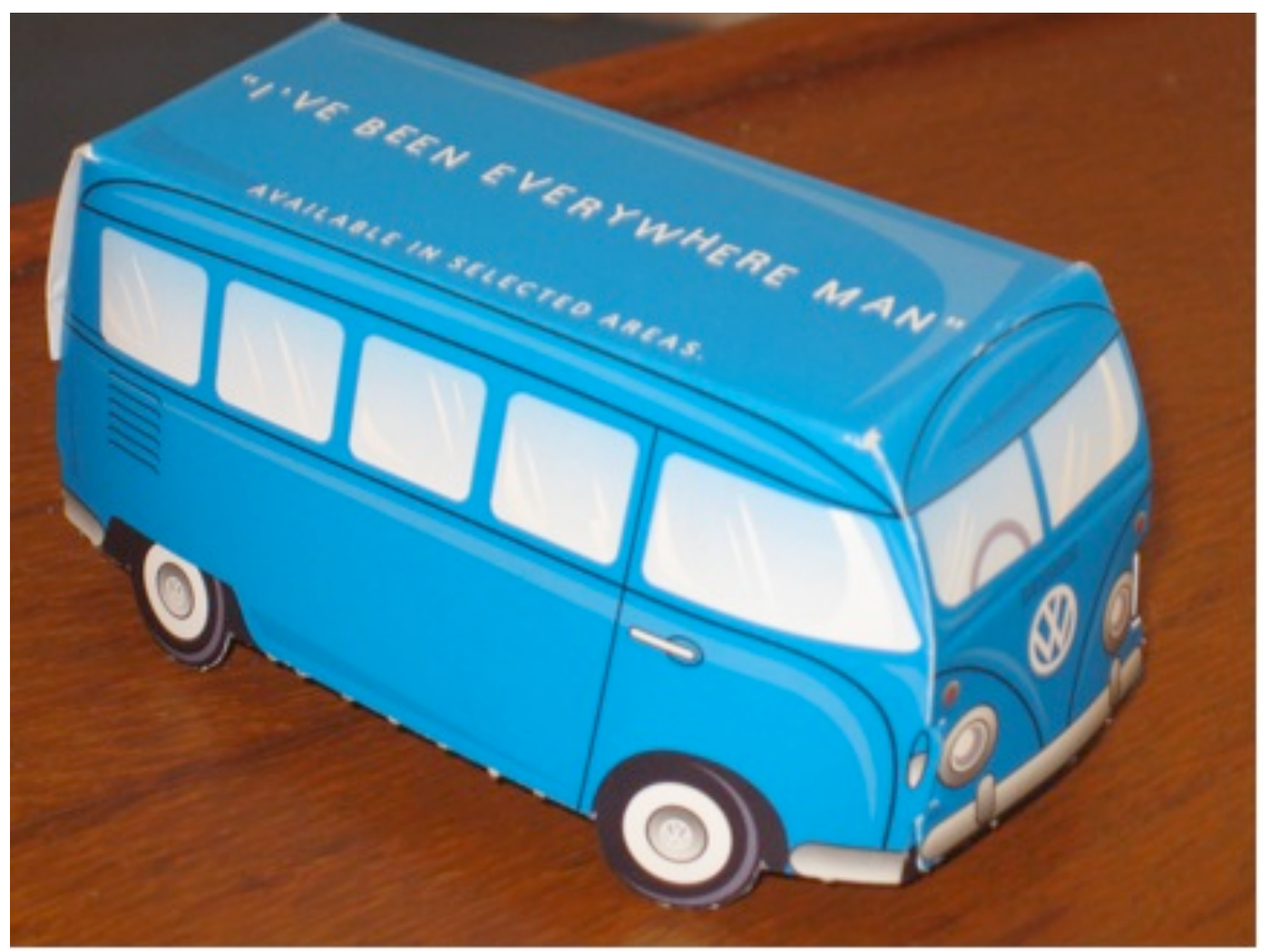

Figure 1: The Bigpond wireless Kombi van, circa 2008 (photograph: Melissa Gregg) 


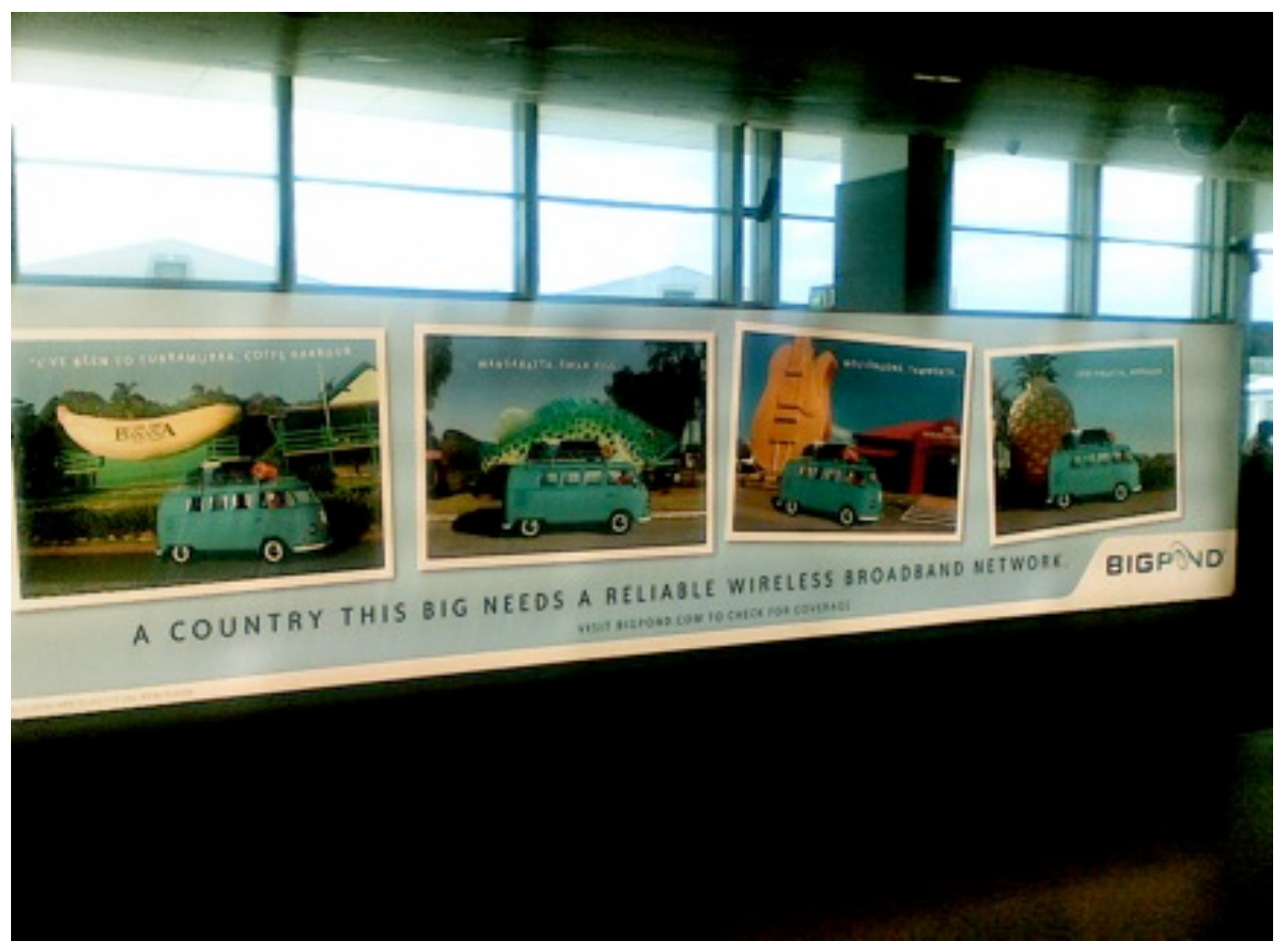

Figure 2: Bigpond wireless advertising at Sydney Domestic, March 2009 (photograph: Melissa Gregg)

The airport installation presumes a familiarity with the Australian version of the popular country song, 'I've Been Everywhere Man', which it illustrates in a series of friezes featuring national landmarks like the Big Banana (a roadside attraction in Coffs Harbour). A folk classic is interpreted anew, a technological innovation is rendered legible through association with the ordinary, and a nation's generic symbols are updated to a newly connected present. Wireless broadband is taken for granted as a reliable expectation in every conceivable location comprising the Australian roadtrip fantasy. The illustrations invite us to disregard the small print on the roof of the cardboard Kombi above, which clearly reads: 'Available in selected areas'.

The Kombi campaign uses a familiar and approachable conduit to capture a number of resonant metaphors for online connectivity. Travelling along the sunny highway, the Kombi is a modest and colloquial adaptation of descriptions of the 
internet as an 'information superhighway'. The many routes travelled by the van echo government policy documents which explain broadband as an infrastructure investment comparable to the rail-building and power-generating schemes that pioneered the nation's economic development. Plus, the freedom of the open road connotes the unlimited potential of the internet, the routes of travel rendered available through the trusty blue 'router'. The Kombi's historical association with alternative lifestyles-of hippie and counter-cultural movements-also suggests liberation of another kind, as if the market power of a large, profit-seeking organisation or the red tape of government regulation has little to do with the radical possibilities to be experienced online.

\section{-PASSING THROUGH}

The perspective favoured in this second campaign is the traveller passing through: someone whose engagement with country towns is serial, superficial and selective. The representation never considers that the rural and regional locations mentioned might be a home rather than a temporary destination. Nor is there any sense that wireless infrastructure is actually an enforced choice for residents. In remote locations, wireless is often the only basis by which one might access the internet. Indeed the latest government announcement means this will almost certainly be the case in a growing number of areas. Instead these images celebrate a transitory relationship with the places mythologised in popular culture and tourism.

Metro-centric marketing of new media technology regularly depicts the bush and the outback as places for urban dwellers to visit on holiday or on weekends, rather than residential nodal points and households in their own right. ${ }^{\text {The }}$ locations in Telstra's wireless campaign are places that one might drive by, stop momentarily, or simply hear about; rarely are they appreciated as generative of culture. In Stewart's terms, they are locations 'out there-in the space of marginalia and ex-centricity' that are nonetheless 'places to which "we" might return-in mind, if not in body-in search of redemption and renewal'. 9 The 'we' in Stewart's formulation can be taken to mean a city-dwelling commentariat, and her history of ethnographic research is a challenge to the ways that remote locations are rendered visible in national histories. Informed by years spent living with Appalachian communities in West Virginia, Stewart's writing considers what it would mean to 
linger in the forgotten places left behind by modernity and other narratives of progress. In these contexts, she asks us to consider 'how culture in an occupied, betrayed, fragmented, and finally deserted place might become not a corpus of abstract ideas of grounded traditions but a shifting and nervous space of desire immanent in lost and re-membered and imagined things'. Against the temptation to mythologise what happens in distant locations, Stewart's writing portrays the complex characteristics shared between people whose worlds exist 'in the space of the gap, in a logic of negation, surprise, contingency, roadblock, and perpetual incompletion'.10

In contrast to recent government policies designed to appease powerful rural voting blocs (witness the previous Coalition Government's attempts to mediate the Telstra-enforced CDMA shut off), and as a response to the selective vision of Telstra's travelling Kombi, Stewart issues us an invitation to contemplate the 'space on the side of the road'. At a time when academic funding models seem destined to allow only piecemeal engagement with communities around the priorities of a university calendar, her work is an exploration of 'how finding oneself on the side of the road could become an epistemological stance'.11

Applied to the present context, and to cite the obvious, neither of the images I've mentioned speaks to a rural constituency or bothers to imagine what connectivity might mean to the communities visited or passed through by others. In the first, the promise of online connectivity is packaged as part of a suburban lifestyle that presumes wealthy (note the number of computers), leisured, nuclear families with stereotypical gender interests. ${ }^{12}$ Telstra's extensive market research clearly corresponds with publicly accessible studies conducted by government agencies that show the presence of school-age children is the principal factor in determining household broadband adoption-followed by income, education, occupation and employment. ${ }^{13}$ These are quantitative measures that justify marketing logics. For these reasons alone the appearance of these images in such volume can be easily dismissed as unremarkable. But, seen another way, they also build a case for asking why broadband would ever be relevant to older citizens, or the poor or unemployed. They beg us to ask how those whose lives remain outside the frame of such 'pictures of staged perfection' cope with the 'exhausting undertow' 
of these and other projections of ordinariness-what emotional effects they have on those whose lifestyle choices don't fit the 'mainstream banality' of corporate cliche. ${ }^{14}$

\section{-NON-METRO MELANCHOLIA}

In the realm of technological imaginaries, in a country where two-thirds of the population live in large metropolitan centres, ${ }^{15}$ non-metro residents share affinities with other marginal identities in the sense that their experiences are so regularly absent from depictions of ordinariness. Rural identity resembles a queer phenomenology if, following the work of Sara Ahmed, we take this to mean negotiating the unhappiness that others feel faced with someone's decision to pursue a different kind of fulfilment. ${ }^{16}$ The non-metro broadband user reckons with an always-present awareness that the images of connectivity promoted in dominant discourses-images that so many others find desirable-may actually appear as uninteresting, if not also uninhabitable. This is because a rural location so often means a lack of access to the facilities that grant these pleasures in the first place. If we were to theorise this condition, what I am calling rural melancholy is the feeling that manifests in the reflex action my title tries to summon: it is the habit of reading the fine print in advertising that says "available in selected metros only".

The non-metro user's melancholia evolves from the knowledge that some of the most highly sanctioned pleasures in life must be disavowed to maintain an attachment to a crucial aspect of identity-the choice of where to live. As Judith Butler explains, in her critique of Freud, identity formation involves negotiating a history of accommodation to abandoned object-choices. Identifications are achieved through the experience of melancholia; that is, the process of developing resilient psychic structures to compensate for 'an original love that, unacknowledged, fails to be resolved'. For Freud, the loss of the object is never absolute because our sense of self expands to incorporate it: 'the other becomes part of the ego through the permanent internalization of the other's attributes'.17 But the exhausting effort of having to take account for the love that cannot be realised makes melancholia a selfpunishing state, because it involves an ongoing process of repressing identification with something desired.

Pressing the analogy to technology advertising, the longed for object (fast broadband, and participation in the pleasures of online connectivity promoted in so 
many business and government policies) creates tension for those who choose to live beyond the capital city bias of current coverage. The shortcomings in actually existing infrastructure lead country residents to variously compensate, make excuses for, and display cynicism in the face of what won't happen, what can't be attained, what isn't guaranteed in the fine print. The barrage of projections celebrating the benefits of broadband summons a form of defense akin to melancholy when the place one lives becomes the very factor preventing access to a vision of happiness. ${ }^{18}$

This non-metro ontology also shares qualities that Lauren Berlant attributes to the 'intimate public' of women's culture. In The Female Complaint she describes women's everyday experience as that of 'disappointment not disenchantment' and her project shows how the genres of sentimentality in women's popular culture alleviate the pain of lost hopes and loves. Berlant claims women offer 'the sacrifice of emotional labor to a variety of kinds of callousness, incompetence, and structural inequity' presented by the rational public sphere and that this involves 'strategies of bargaining, adaptation, and flouting the rules'. Similarly, the ways that rural technology users 'make do' with infrastructure limitations and the inequalities resulting from government and market failure recalls the poignant potential Berlant sees in women's culture. Each group sustains itself in the belief that "tomorrow is another day" in which fantasies of the good life can be lived'.19

\section{-RATIONAL SUBJects}

Here, I am consciously avoiding a discussion of whether in fact rural consumers do or should desire high-speed broadband given the wider economic transformations affecting everyday life. Any casual review of opinion pages in today's newspapers will almost overwhelmingly suggest otherwise-that online connectivity is far from the highest priority for many residents beyond the city. But part of my point in drawing attention to affect is to indicate the limitations of engaging in cultural policy debates in these conventional ways-when to do so involves manifesting an articulate, rational speaking position performed in appropriate public sphere locations; a subjectivity that knows well enough to place a potentially infinite number of political causes in the right order of urgency and in a language fitting public submissions and stakeholder lobbying. In this situation, with the odds so 
heavily poised against the majority of rural residents effectively expressing their reactions to Government policy, cultural research contributes something vital by explaining the bases for political dis-engagement or, in Berlant's words, 'what is absorbing in the defensive, inventive, and adaptive activity of getting by, along with the great refusals to go through power to attain legitimacy'. ${ }^{20}$ Affective registers are a counter to the linguistic challenge of saying anything truly meaningful through quantitative representations of rural experience that inform public policy. For despite the best intentions of government initiatives and telco provisions targeting 'rural and regional Australia', there is still a symbolic violence in this notoriously slippery category, which assumes a shared horizon of values among inhabitants of places as geographically, demographically and historically different as Hobart, Coober Pedy and Rockhampton. Non-metro melancholia, by contrast, offers a means to register the 'structure of feeling' shared across a range of rural, regional and provincial locations. ${ }^{21}$

As Berlant has long argued, the risk of creating political 'publics' is that categorisation has the effect of making diverse individuals appear generic:

it turns them into kinds of people who are both attached to and underdescribed by the identities that organize them. This paradox of partial legibility is behind much of the political and personal anger that arises in scenes of misrecognition in everyday life. ${ }^{22}$

Applied to the present context, much of the anger surrounding the plans for the national broadband network stems from the perception that city policy makers fail to notice the different priorities that exist in rural areas, which affect the kind of services that are seen as valuable. Some of the most pressing concerns-changes to climate, access to employment, and population makeup-at least deviate from the office-based schedules pushing many improvements in information and communications technology (ICT) design. They are certainly distant from the entertainment preferences of young urban users who are cherished because wealthy demographics are driving the demand for faster broadband. To make rural connectivity more than an ambiguous promise means seriously coming to terms with the daily habits and routines of those who don't work in jobs in suburbs or city centres, who might not aspire to visit these centres in response to the boom in 
regional tourism, and whose everyday life may be blissfully free of computer dependence.

Cultural research can reflect the different forms of social capital, expertise and authority that operate as influencers in rural areas. Think, for instance, of the civic institutions that have flourished across Australia's diverse landscape over the past century-from Rotary to the Returned and Serviceman's League (RSL), churches to parents' and citizens' groups, and volunteer groups like the Country Women's Association (CWA). ${ }^{23}$ These affiliations question fundamental assumptions about the benefits of the digital economy, particularly the notion that online connection is the best form of social networking. And if it is these organisations that provide the community solace and support for rural residents that online fora often replace in urban contexts, it is little coincidence that they face declining memberships as ever greater numbers of civic services are reduced to an internet presence. Combined with the wider economic changes affecting employment opportunities in rural areas (including the significant potential for education and class mobility now available to women), the fortunes of conservative institutions that remain attached to local identity will not be magically reversed with the take-up of broadband. Nonetheless, rural cultural studies attentive to these tensions can contribute to the landscape for telecommunications policy by demonstrating how 'ordinary restlessness appears as a symptom of ambivalence about aspirational normativity and not a pointer toward unrealized revolution'.24 From this perspective, that rural residents have yet to mobilise in protest against the selectivity of broadband coverage is hardly a failure of nerve. It is rather a reflection on the ways that the promise of online connectivity is represented as so uncompelling in its modes of sociality, while simultaneously harbouring a threat to other ways of living.

\section{—CULTURES OF CONNECTIVITY}

Looking beyond the national, Genevieve Bell shows how a comparative approach that accounts for different cultures of connectivity can reveal what technology can and does look like given specific local customs. ${ }^{25}$ Cultural research can bear witness to the many ways connectivity is actualised through co-operative, activist, mystic, religious and community-driven initiatives, all of which contrast the individualised, 
consumerist and market-driven priorities shaping Australian government and business strategy. ${ }^{26}$ Bell shares with Stewart a training in anthropological method, and each provides an example of the long-term investment in research that is necessary to appreciate and learn from the unique dynamics of rural and regional life. ${ }^{27}$ Cultural research of this kind slows down the research and activist agenda around technology use to hear the concerns of residents expressed in their own terms.

To re-present the 'space on the side of the road', Stewart writes: we need more than assertions that the local has its own epistemology or that everything is culturally constructed. We need to approach the clash of epistemologies-ours and theirs-and to use that clash to repeatedly reopen a gap in the theory of culture itself so that we can imagine culture as a process constituted in use and therefore likely to be tense, contradictory, dialogic, texted, textured, both practical and imaginary, and in-filled with desire. That is, the theory of culture itself must be brought into the space of the gap between signifier and meaning-the 'space on the side of the road'-so that we can begin to imagine it as a 'thing' that is not selfidentical with itself but given to digression, deflection, displacement, deferral, and difference. ${ }^{28}$

Stewart demonstrates the value of ethnographic research in opening up a 'gap in the order of things', that will recognise the range of experiences to be found in any specific place.

My choice of the term 'non-metro' to discuss rural melancholy is therefore not intended to reify or prolong the present interest in 'rural cultural studies', much less essentialise any notion of what the feeling of a rural or non-metro location involves for all people. Instead it is an appreciation of the significance of ordinary affects that escape representation for profitable or quantifiable outcomes. Drawing on feminist and queer theory, my aim has also been to highlight the links that can be made between the banal imagery of advertising copy for technology access and visions of empowerment and fulfilment that pertain to other contexts. The affects of rural identity resemble those of other minority subjectivities to the extent that each suffers a differential relationship to the default pleasures and benefits of citizenship. 
In her critique of Freud's model of melancholia, Butler famously calls for a multiplicity of dissonant variations on gender identity-acts of 'gender trouble'-to negate the melancholy apparently innate to normative gender ascription. This is a suggestion that might be extended to current figurations of rural identity, which rarely offer positive or complex representations of rural life and fulfilment that might compete with those imagined in metro-centric advertising. Cultural studies research informed by ethnographic principles offers a means to recognise the different priorities of rural life and how they differ from an individualised, screenbased, indoor lifestyle. It can constitute an effort to produce a multiplicity of rural identities with equal purchase on what constitutes a worthy vision of community and happiness.

The Australian Government's broadband plan is an important acknowledgement that the benefits of internet access so far overwhelmingly favour affluent city dwellers. It hardly seems sustainable for a nation to perpetuate a major gulf between those who see harmony in a shared broadband connection ('we all get on when we all get on') and those who seek to build community networks through other avenues. To continue this division would mean that the city and the country need never encounter each other's difference, just as it would leave less populated areas vulnerable to economic appraisals of their worth. The government's latest actions at least appreciate that it is not in the market's interest to deliver the promise of connectivity in equal measure.

Announcing the revised policy, Prime Minister Kevin Rudd visited Tasmania, Australia's smallest state, which has been earmarked for the first phase of the government's new venture. As my childhood home for over twenty years, and the place I often return to see my family, Tasmania's parochial media outlets and monopolised telecommunications infrastructure are the basis for many of these musings about rural melancholy. Seizing the limelight in a press conference shared with the Prime Minister in April 2009, Tasmanian Premier David Bartlett explained how the government's broadband vision fit his hopes for Tasmania as a 'clever, kind and connected' society. However cloying the soundbite, his slogan set a benchmark for local politicians seeking to capitalise on the links between citizenship and connectivity. 
Bartlett's hope is commendable in the present climate for the sheer novelty of choosing to articulate values in addition to the inherent worth of broadbandincluding the value to be found in the affective. Yet in the dwindling months before forthcoming elections, these highly rhetorical celebrations of the revolutionary promise of online pleasures continue to hover in a state of animated suspension. For non-metro broadband users, the future that is about to happen ${ }^{29}$ is tantalising and elusive, like somebody's favourite web page that, because of the unaccountable logistics of telecommunications infrastructure, takes too long to load. Politicians pitching their fortunes on the new knowledge economy would do well to note that, whether one's allegiance is to country or the city, the gap between image and reality is a place few residents seek to dwell. In contrast to the quality of Australia's internet access, if there was any doubt that melancholy might be political, we could do no better than witness the speed with which these leaders loudly declare another form of community for voters to believe in should their hopes be deferred much longer.

Melissa Gregg works in the Department of Gender and Cultural Studies at the University of Sydney. Her books include Cultural Studies' Affective Voices (2006) and The Affect Theory Reader (edited with Greg Seigworth, 2010). Melissa's three-year study of online technology, work and home life, Work's Intimacy, is to be published in 2010.<mgregg@usyd.edu.au>

\footnotetext{
-NOTES

${ }^{1}$ Kathleen Stewart, Ordinary Affects, Duke University Press, Durham and London, 2007, p. 4.

2 Stewart, Ordinary Affects, p. 5.

3 Raymond Williams, The Country and the City, Paladin, Frogmore, 1975.

4 Melissa Gregg, Scholarly Affect: Voices of Intervention in Cultural Studies, PhD thesis, University of Sydney, 2004. Published as Cultural Studies' Affective Voices, Palgrave Macmillan, Basingstoke, 2006.

${ }^{5}$ Lauren Berlant, The Female Complaint: The Unfinished Business of Sentimentality in American Culture, Duke University Press, Durham and London, 2008, p. 25.

${ }^{6}$ My use of the word 'typical' is a reference to the deliberately vague wording of Telstra's own fine print for this advertisement, which warns 'Signal range varies from house to house but access is from anywhere in a typical house'.

7 I thank Anna Hickey-Moody for noticing this and for many other encouraging comments on the draft of this paper. Also thanks to Michelle Dicinoski for pragmatic and poetic inspiration.
} 
${ }^{8}$ See Melissa Gregg and Genevieve Bell, “'Through Country Women”: A Proposal for the CWA's Role in Rural Connectivity', in Record of the Communications Policy \& Research Forum 2008, Network Insight Institute, available at:

<http://ww.networkinsight.org/publications/record_of_the_2008_cprf.html/group/6>.

${ }^{9}$ Kathleen Stewart, A Space on the Side of the Road: Cultural Poetics in an 'Other' America, Princeton

University Press, Princeton, 1996, p. 5.

10 Stewart, A Space on the Side of the Road, p. 17.

11 Stewart, A Space on the Side of the Road, p. 34.

12 Right down to the mother using the internet to look up recipes online, and the pink and blue bedrooms of the children.

13 Lesley Osborne, 'Being Connected: Australians' Take-up and Use of Broadband', presentation on behalf of Australian Communications and Media Authority (ACMA) to Self, Place, and Broadband Connectivity: Making and Making Do Workshop, University of Wollongong, 12 February 2009.

14 Stewart, Ordinary Affects, p. 27.

15 I thank the anonymous reviewer who emphasised this point. To clarify, my use of the term 'nonmetro' has synergies with previous work in gender and cultural studies interested in contesting 'metronormative' assumptions. See, for instance, Judith Halberstam, In a Queer Time and Place: Transgender Bodies, Subcultural Lives, New York, New York University Press, 2005; and Jane Kenway, Anna Kraack and Anna Hickey-Moody, Masculinity Beyond the Metropolis, Palgrave Macmillan, Basingstoke, 2006. While I am not specifically drawing on the social science traditions that also use 'metropolitan' terminology, I do hope this essay contributes to further cross-disciplinary discussions where 'place' and 'culture' are shared objects of analysis (in line with the aims of this special issue). 16 Sarah Ahmed, Queer Phenomenology: Orientations, Objects, Others, Duke University Press, Durham and London, 2006, and 'Happy Objects', in Melissa Gregg and Greg Seigworth (eds), The Affect Theory Reader, Duke University Press, Durham and London (forthcoming 2010).

17 Judith Butler, Gender Trouble: Feminism and the Subversion of Identity, Routledge, New York, 2006, See especially pp. 19, 63.

18 The analogy to Ahmed's theory of queer identity is clear if we think of her depiction of concerned parents, who don't reject a son or daughter for being gay, but worry that happiness will be all the more difficult to achieve because of the way the child 'chooses' to live. See Ahmed, 'Happy Objects'.

19 Berlant, Female Complaint, p. 2.

20 Berlant, Female Complaint, p. 27.

${ }^{21}$ Raymond Williams, Politics and Letters: Interviews with New Left Review, Verso, London, 1981.

22 Lauren Berlant, The Queen of America Goes to Washington City: Essays on Sex and Citizenship, Duke University Press, Durham, 1997, p. 2.

23 For international readers, the RSL of Australia is committed to the well-being of war veterans and their families, while the CWA is a women-only volunteer organisation specialising in grassroots fundraising for improving the conditions of rural women. Both institutions often occupy prominent locations in Australian country towns and serve as regular meeting points for local activities.

24 Berlant, Female Complaint, p. 27.

25 Genevieve Bell, 'The Many Futures of Our Digital Lives', Inaugural Public Lecture, South Australia Thinker in Residence, Adelaide, 27 November 2008, available at:

<http://www.thinkers.sa.gov.au/gbell_events.html>

${ }^{26}$ For more on the co-operative, mystic and religious in wireless broadband policy, see Gerard Goggin and Melissa Gregg, 'Wireless Cultures and Technologies', Media International Australia, no. 125, November 2007.

27 See 'South Australian Stories', Bell's Thinker in Residence project of 2008-09 attempted to gather one million stories of South Australian residents' use of communications technology: 
$<$ http://www.sastories.com/>. Initial findings from the study can be heard in a later lecture in the residency, "Getting from Here to There?" available on the Thinker in Residence website,

$<$ http://www.thinkers.sa.gov.au/gbell_events.html>.

28 Stewart, A Space on the Side of the Road, p. 5.

${ }^{29}$ Brian Massumi, 'The Future Birth of the Affective Fact', in Melissa Gregg and Grgeory J. Seigworth (eds), The Affect Theory Reader, Duke University Press, Durham (forthcoming, 2010). 